\title{
INFLUÊNCIA DA CONCENTRAÇÃO INICIAL DE AÇÚCAR NA FERMENTAÇÃO ALCOÓLICA DO SUCO DE MELÃO
}

\author{
J. M. M. HENRIQUE ${ }^{1}$, N. C. G. SILVA $^{1}$ e A.D.T. PINHEIRO ${ }^{1}$ \\ ${ }^{1}$ Universidade Federal Rural do Semi-Árido, Departamento de Agrotecnologia e Ciências Sociais \\ E-mail para contato: alvaro_eq@hotmail.com
}

\begin{abstract}
RESUMO - Com boa disponibilidade na região nordeste e apresentando baixo custo, o melão foi empregado como insumo da fermentação alcoólica, sendo seu suco fermentado por meio da levedura Saccharomyces cerevisiae. Com a finalidade de se obter a concentração de açúcar que maximize o rendimento fermentativo e minimize a formação de subprodutos, foram realizados ensaios utilizando Erlenmeyers de $500 \mathrm{~mL}$. Para tanto, utilizou-se incubadora tipo shaker a $150 \mathrm{rpm}$ e $30{ }^{\circ} \mathrm{C}$ por um período de dez horas, sendo a faixa de concentração inicial de açúcar estudada entre 100 e 180 g.L ${ }^{-1}$. Para concentrações de açúcar superiores a 140 g. $\mathrm{L}^{-1}$, observou-se o aparecimento de efeitos inibitórios, sendo estes refletidos na diminuição do rendimento do processo fermentativo para concentrações superiores. Para a faixa de 100 a 140 g. $\mathrm{L}^{-1}$, observou-se que o rendimento permaneceu em torno de $93 \%$. Assim, a concentração inicial de substrato de 100 g. $\mathrm{L}^{-1}$ foi escolhida como ótima devido ao fato de conseguir-se o mesmo rendimento utilizando, porém, menor quantidade de substrato.
\end{abstract}

\section{INTRODUÇÃO}

Considerado um processo industrial essencial na obtenção de álcool etílico, a fermentação alcoólica ocorre na ausência de oxigênio, sendo a mesma catalisada por enzimas, as quais auxiliam a transformação de açúcares em etanol e $\mathrm{CO}_{2}$. Em geral, as fermentações alcoólicas são conduzidas por leveduras, sendo a mesma compreendida por várias operações para sua efetivação, como tratamento da matéria-prima, preparo do meio de crescimento e produção, esterilização do mesmo, consecução do produto através do consumo de substrato, separação e purificação do mesmo, entre outros (KOSARIC, 1996).

Diversos fatores influenciam no crescimento de micro-organismos e determinam o tipo de metabolismo que irão exibir, tais como temperatura, $\mathrm{pH}$, concentração inicial de células e concentração inicial de substrato (açúcar) (LIMA, BASSO e AMORIM, 2001). Além disso, valores não ideais desses parâmetros, intrínsecos a cada tipo de processo fermentativo, afetam a eficiência de conversão de substrato em produto, ou seja, o rendimento da fermentação.

Nos processos fermentativos, a presença de açúcar é essencial no meio de cultura, sendo parte destinada à conversão em álcool por ação das leveduras e o resto exercerá influência significativa na qualidade do produto final (ZINGLER et al., 2009). Chaptalizar consiste no processo de acrescentar 


\section{9 a 22 de outubro de 2014 \\ Florianópolis/SC}

açúcar ao mosto de forma a aumentar a quantidade total de açúcar e assim elevar o potencial teor de álcool. Conforme modelo de Monod, o aumento na concentração inicial de substrato exibe uma cinética de crescimento celular do tipo saturação. Um gradativo acréscimo na concentração de açúcar extrapola essa região de saturação e concede à fermentação um efeito inibitório pelo substrato, causando assim a desativação de enzimas e, como dito anteriormente, modifica o caminho metabólico do micro-organismo. Quando a concentração ultrapassa $150 \mathrm{~g} . \mathrm{L}^{-1}$, há ocorrência do efeito inibidor por parte do substrato (THATIPAMALA, ROHAI e HILL, 1992).

Na obtenção de álcool, os principais micro-organismos utilizados são as leveduras, uma vez que são economicamente viáveis e apresentam bom rendimento do processo. O gênero Sacharomyces cerevisiae pertence ao grupo de leveduras mais utilizadas na indústria, pois se trata de um organismo vivo, com múltiplas habilidades metabólicas, podendo alterar a estequiometria quando ocorrem alterações no meio e assim afetar diretamente a conversão de açúcar em etanol (LIMA, BASSO e AMORIM, 2001). No Brasil, são usualmente empregadas como agentes de bioprocessos na produção de álcool, na panificação e na elaboração de bebidas como cerveja, vinho e cachaça (MACEDO, 1993).

As leveduras necessitam de nutrientes para seu crescimento, manutenção e reprodução (AMORIM; LEÃO, 2005), uma vez que os mesmos encontram-se presentes na matéria-prima utilizada como substrato na fermentação, juntamente com umidade e açúcares. Por apresentar tais requisitos, elevado teor de sólidos solúveis, boa disponibilidade durante todo o ano no nordeste brasileiro e preço bastante acessível, o melão (Cucumis melo L.) apresenta-se como um insumo promissor na fermentação alcoólica. Além disso, seu uso na fabricação de produtos não tradicionais, como o vinho de frutas, visa o aproveitamento do excesso de safras, agrega valor ao mesmo e apresenta potencial geração de empregos.

Dentro desse contexto, o presente estudo teve como objetivo obter a concentração de açúcar que maximize o rendimento da fermentação e minimize a formação de subprodutos na elaboração de fermentado alcoólico a partir do suco extraído do melão (Cucumis melo L.).

\section{METODOLOGIA}

\subsection{Micro-organismo}

A levedura Saccharomyces cerevisiae utilizada nos ensaios experimentais foi isolada a partir de uma levedura comercial (FLEISCHMANN - AB BRASIL INDUSTRIAL E COMÉRCIO DE ALIMENTOS LTDA).

\subsection{Meios de cultura}

Para fins de manutenção, propagação e obtenção do inóculo, preparou-se uma solução de YEPD (Yeast Extract-Peptone-Dextrose), ou seja, meio complexo constituído por 10 g.L $\mathrm{L}^{-1}$ de Extrato de Levedura, 20 g. $\mathrm{L}^{-1}$ de Peptona e 30 g. $\mathrm{L}^{-1}$ de Glicose. $\mathrm{O}$ pH do meio foi ajustado para 4,5 utilizando ácido sulfúrico P.A., sendo a esterilização realizada em autoclave a $110{ }^{\circ} \mathrm{C}$ por um período de tempo 


\section{9 a 22 de outubro de 2014 \\ Florianópolis/SC}

de 10 minutos.

A inoculação foi conduzida em ambiente estéril, especificamente em uma câmara de fluxo laminar, e a incubação realizada em Erlenmeyers, posteriormente colocados em um agitador orbital da marca Tecnal, modelo TE-420, sob as seguintes condições: velocidade de agitação de $150 \mathrm{rpm}$, temperatura a $30^{\circ} \mathrm{C}$ por um período de $24 \mathrm{~h}$. Em seguida, o inóculo foi filtrado a vácuo na câmara de fluxo laminar para obter a concentração celular desejada para o ensaio fermentativo.

\subsection{Preparação do suco de melão}

Para obtenção do suco, retirou-se sua casca e sementes e em seguida, o melão foi cortado em cubos, os quais foram triturados para a obtenção da polpa. Seu pH foi ajustado com ácido sulfúrico P.A. para 4,5 e sua esterilização se deu em autoclave a $110{ }^{\circ} \mathrm{C}$ por $10 \mathrm{~min}$.

\subsection{Chaptalização}

Para o estudo da influência da concentração inicial de substrato, adicionou-se Glicose P.A. de forma a aumentar a concentração de açúcar presente no suco de melão. Os ensaios fermentativos foram realizados com 100, 115, 140 e $180 \mathrm{~g} . \mathrm{L}^{-1}$ de substrato inicial (glicose+frutose).

\subsection{Fermentação alcoólica}

A fermentação alcoólica ocorreu em frascos de Erlenmeyer de $500 \mathrm{~mL}$, utilizando $250 \mathrm{~mL}$ de suco de melão como meio de cultura e 7 g.L $\mathrm{L}^{-1}$ de concentração da levedura Saccharomyces cerevisiae, conduzidas em shaker (Tecnal - TE 420) sob agitação de $150 \mathrm{rpm}$ por um período de $10 \mathrm{~h}$ e $30{ }^{\circ} \mathrm{C}$. Amostras foram retiradas em intervalos de tempo pré-definidos para serem analisadas, sendo as alíquotas coletadas na câmara de fluxo laminar para que não houvesse contaminação.

\subsection{Métodos analíticos}

Concentração celular: Para mensurar a concentração de biomassa, fez-se uso da densidade óptica (D.O.) a $410 \mathrm{~nm}$ com auxílio de um espectrofotômetro. Esse método é baseado na medida da turvação de uma solução em função da quantidade de células em suspensão, sendo simples e rápida a sua execução.

Concentração de substrato e produto: Para mensurar as concentrações de substrato e produtos, utilizou-se cromatógrafo líquido de alta eficiência - CLAE (Waters, Milford, MA, EUA) equipado com um detector de índice de refração Waters 2414 e com uma coluna Aminex HPX-87H (Bio-Rad, Hercules, CA, EUA). Ácido Sulfúrico $5 \mathrm{mmol} . \mathrm{L}^{-1}$ foi usado como fase móvel (eluente) na vazão de $0,5 \mathrm{~mL} \cdot \mathrm{min}^{-1} \mathrm{a} 65^{\circ} \mathrm{C}$, sendo o volume de injeção das amostras de $20 \mu \mathrm{L}$.

Cálculo dos rendimentos e parâmetros cinéticos: A partir dos ensaios experimentais, obtiveramse os dados necessários (concentração de biomassa, substrato, produto) para determinação dos parâmetros cinéticos da fermentação alcoólica, tais como velocidade específica de crescimento $\left(\mu_{\text {máx }}\right)$, 
conversão de célula em produto $\left(\mathrm{Y}_{\mathrm{p} / \mathrm{x}}\right)$, conversão de substrato em célula $\left(\mathrm{Y}_{\mathrm{x} / \mathrm{s}}\right)$, conversão, eficiência e produtividade.

\section{RESULTADOS E DISCUSSÃO}

No intuito de analisar a influência da suplementação do suco de melão com açúcar, avaliou-se o consumo de substrato, o crescimento celular e a produção de etanol para as concentração inicial de açúcar de 100, 115, 140 e 180 g.L ${ }^{-1}$, sendo o resultado mostrado na Figura 1.

Em análise a Figura 1, observa-se que ao utilizar o meio com 180 g.L $\mathrm{L}^{-1}$ de substrato inicial, verifica-se que após $10 \mathrm{~h}$ de fermentação nem todo o açúcar é consumido, sobrando aproximadamente 70 g.L. $\mathrm{L}^{-1}$. Já no ensaio fermentativo de 100 g.L $\mathrm{L}^{-1}$, todo o substrato foi consumido após 8 horas de fermentação. A maior produção de etanol $\left(68,17\right.$ g. $\left.\mathrm{L}^{-1}\right)$ foi alcançada quando utilizou-se o meio contendo 140 g.L. $\mathrm{L}^{-1}$ de substrato inicial, ao passo que a menor $\left(47,94\right.$ g.L $\left.\mathrm{L}^{-1}\right)$ foi obtida para 100 g.L $\mathrm{L}^{-1}$.
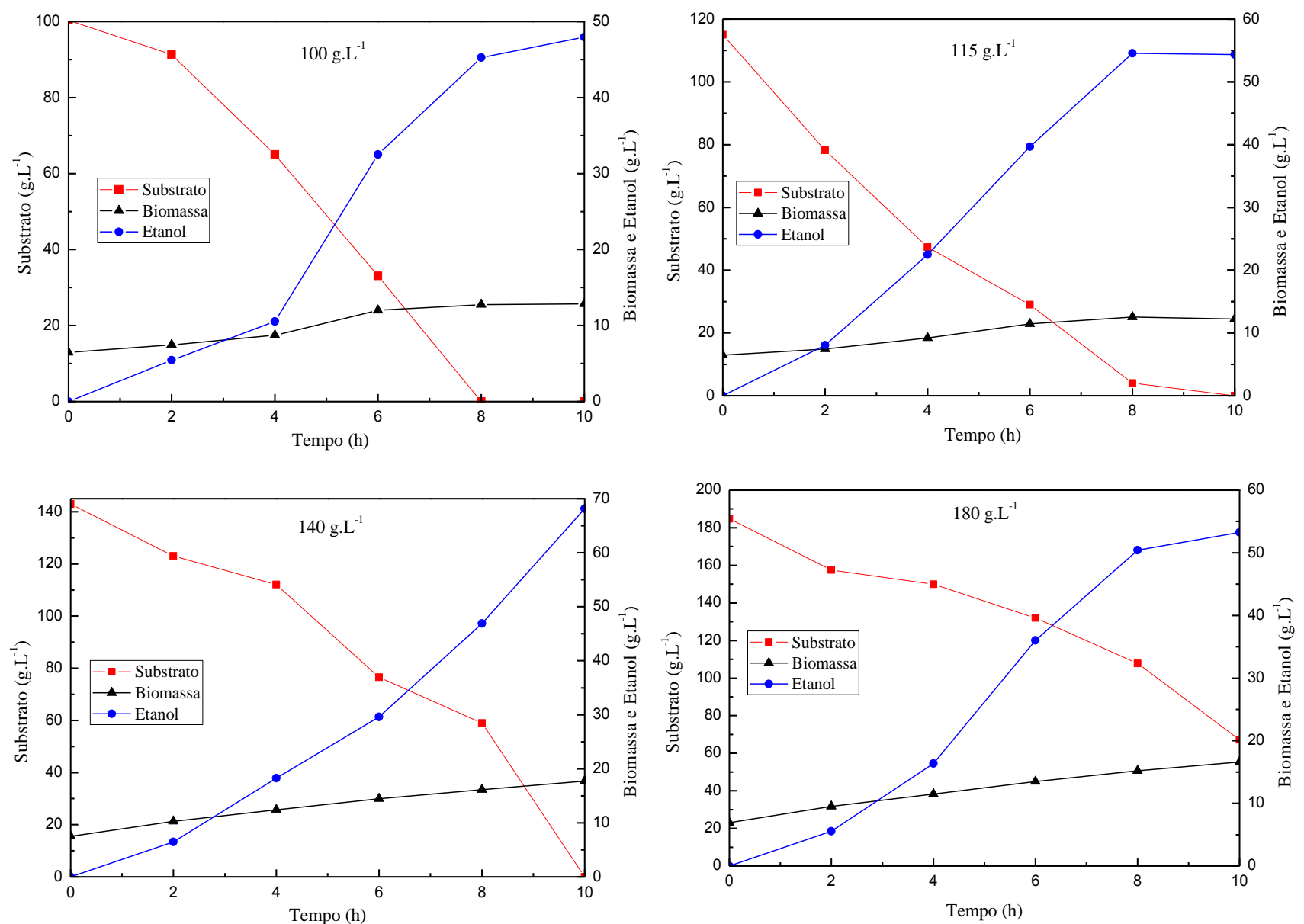

Figura 1 - Efeito da suplementação do suco de melão para a produção de etanol por Saccharomyces cerevisae a $30{ }^{\circ} \mathrm{C}$ e $150 \mathrm{rpm}$. 
A Tabela 1 denota os parâmetros cinéticos resultantes da fermentação alcoólica usando a levedura industrial Saccharomyces cerevisae ao empregar quatro diferentes valores de concentração inicial de substrato (glicose + frutose) nos ensaios experimentais: $100,115,140$ e 180 g.L $\mathrm{L}^{-1}$. Observase que a máxima velocidade específica de crescimento $\left(\mu_{\text {máx }}\right)$ apresentou um progressivo aumento com a elevação da concentração de substrato inicial (Tabela 1). Os parâmetros de conversão de substrato em célula $\left(\mathrm{Y}_{\mathrm{X} / \mathrm{S}}\right)$ e célula em produto $\left(\mathrm{Y}_{\mathrm{P} / \mathrm{X}}\right)$ apresentaram comportamentos distintos. Enquanto o primeiro apresenta um pequeno aumento no valor de $\mathrm{Y}_{\mathrm{X} / \mathrm{S}}$ com o aumento da concentração inicial de substrato, o $\mathrm{Y}_{\mathrm{P} / \mathrm{X}}$ apresenta valores decrescentes. Quanto ao rendimento $(\eta)$, o mesmo permanece praticamente inalterado (aproximadamente 93\%) para a faixa de 100 a 140 g.L. ${ }^{-1}$, assumindo valor inferior $(88,62 \%)$ para a concentração de 180 g.L $\mathrm{L}^{-1}$. Assim, pode-se supor o aparecimento de algum tipo de inibição para 180 g.L. $\mathrm{L}^{-1}$. Esse resultado pode ser observado também para a produtividade, a qual apresenta aumento entre 100 e 115 g.L $\mathrm{L}^{-1}$, torna-se fixa entre 115 e 140 g. $\mathrm{L}^{-1}$, passando então a cair em 180 g.L $\mathrm{L}^{-1}$.

Tabela 1 - Parâmetros cinéticos obtidos para a levedura Saccharomyces cerevisae para diferentes concentrações inicias de substrato na fermentação alcoólica do suco de melão

\begin{tabular}{c|c|c|c|c}
\hline \multirow{2}{*}{ Parâmetros Cinéticos } & \multicolumn{4}{|c}{ Concentração inicial de substrato } \\
\cline { 2 - 5 } & $100 \mathrm{~g} \cdot \mathrm{L}^{-1}$ & $115 \mathrm{~g} \cdot \mathrm{L}^{-1}$ & $140 \mathrm{~g} . \mathrm{L}^{-1}$ & $180 \mathrm{~g} . \mathrm{L}^{-1}$ \\
\hline$\mu_{\text {máx }}\left(\mathrm{h}^{-1}\right)$ & 0,075 & 0,097 & 0,126 & 0,126 \\
$\mathrm{Y}_{\mathrm{X} / \mathrm{S}}(\mathrm{g} / \mathrm{g})$ & 0,064 & 0,050 & 0,072 & 0,082 \\
$\mathrm{Y}_{\mathrm{P} / \mathrm{X}}(\mathrm{g} / \mathrm{g})$ & 7,498 & 9,429 & 6,659 & 5,489 \\
$\mathrm{Y}_{\mathrm{P} / \mathrm{S}}(\mathrm{g} / \mathrm{g})$ & 0,478 & 0,472 & 0,477 & 0,453 \\
$\eta(\%)$ & 93,490 & 92,446 & 93,302 & 88,620 \\
$\mathrm{Q}_{\mathrm{P}}(\mathrm{g} / \mathrm{L} \cdot \mathrm{h})$ & 4,794 & 6,820 & 6,817 & 5,325 \\
\hline
\end{tabular}

\section{CONCLUSÃO}

A concentração inicial de substrato mostrou-se bastante influente no rendimento do processo de fermentação alcóolica do suco de melão por Saccharomyces cerevisae. Os melhores resultados obtidos na conversão de substrato em produto e no rendimento da fermentação, encontram-se numa faixa de concentração entre 100 e 140 g.L $\mathrm{L}^{-1}$. Contudo, ao utilizar 140 g.L. $\mathrm{L}^{-1}$, obtêm-se uma maior concentração de etanol (aproximadamente 70 g. $\mathrm{L}^{-1}$ ), mantendo-se o rendimento em álcool do processo praticamente inalterado (em torno de 93\%). Logo, pode-se concluir 140 g.L é a $^{-1}$ concentração inicial de substrato que maximiza a produção de etanol.

\section{REFERÊNCIAS}

AMORIM, H. V.; LEÃO, R. M. Fermentação alcoólica, ciência e tecnologia. Piracicaba, Fermentec, 2005, 448 p. 
KOSARIC, N. J.; REED, G.; PÜHLER, A.; STADLER, P. Products Etanol - Potential source of energy and chemical products. In: Rehm, H. of primary metabolism - Botechnology. 2 ed., V ch, p.121-203, 1996.

LIMA, U. A.; BASSO, L. C.; AMORIM, H. V. In: LIMA, U. A. (Coord.). Biotecnologia Industrial: Processos Fermentativos e Enzimáticos. São Paulo: Editora Edgard Blücher, v. 3, p. 1-43, 2001.

MACEDO, L. C. H. Álcool Etílico. São Paulo: Editora ICONI, p.157, 1993.

THATIPAMALA, R.; ROHAI, S.; HILL, G. A. Effects of high product and substrate inhibition on the kinects in biomass and products yields during ethanol batch fermentation. Biotechnol. Bioeng.; v.40, n.2, p.289-297, 1992.

ZINGLER, F. M.; CARLESSO, F.; RIBEIRO, G. R.; TERRA, L. M. Processo de fermentação alcoólica e caracterização do fermentado de butiá (Butia eriospatha Mart. Ex Drude). VIII Congresso Brasileiro de Engenharia Química em Iniciação Científica, Uberlândia - MG, 2009. 